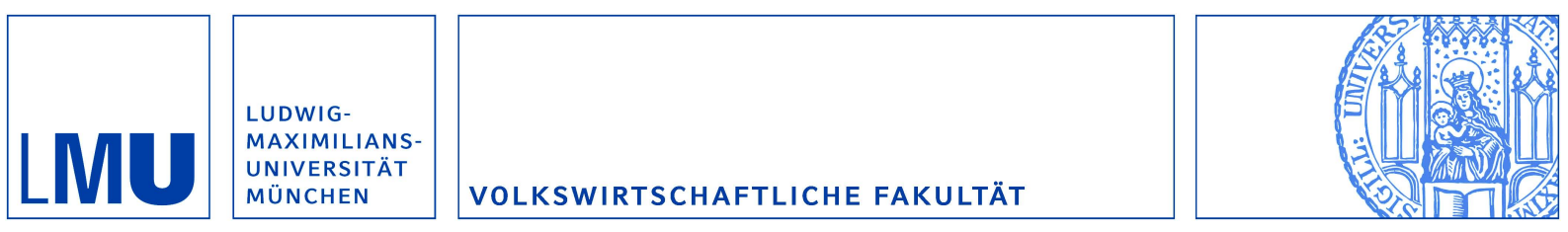

Bauer, Christian; Davies, Ronald B. und Haufler, Andreas:

Economic integration and the optimal corporate tax structure with heterogeneous firms

Munich Discussion Paper No. 2011-14

Department of Economics

University of Munich

Volkswirtschaftliche Fakultät

Ludwig-Maximilians-Universität München

Online at https://doi.org/10.5282/ubm/epub. 12310 


\title{
Economic integration and the optimal corporate tax structure with heterogeneous firms*
}

\author{
Christian Bauer \\ University of Munich
}

\author{
Ronald B. Davies \\ University College Dublin
}

\author{
Andreas Haufler \\ University of Munich
}

August 2011

\begin{abstract}
We study the optimal combination of corporate tax rate and tax base in a model of a small open economy with heterogeneous firms. We show that it is optimal for the small country's government to effectively subsidize capital inputs by granting a tax allowance in excess of the true costs of capital. Economic integration reduces the optimal capital subsidy and drives low-productivity firms from the small country's home market, replacing them with high-productivity exporters from abroad. This endogenous policy response creates a selection effect that increases the average productivity of home firms when trade barriers fall, in addition to the well-known direct effects.
\end{abstract}

Keywords: corporate tax reform, trade liberalization, firm heterogeneity JEL Classification: H25, H87, F15

*Paper presented at the Public Economic Theory (PET) meeting in Bloomington, Indiana and at the congress of the International Institute for Public Finance in Ann Arbor, Michigan. We thank conference participants, in particular Robert Cline and Michael Devereux for helpful comments. Bauer and Haufler gratefully acknowledge financial support from the German Research Foundation (Grant No. HA 3195/8).

e-mail addresses: Bauer: christian.bauer@lrz.uni-muenchen.de. Davies: ronbdavies@gmail.com. Haufler: andreas.haufler@lrz.uni-muenchen.de. 


\section{Introduction}

Corporate tax reform has been a core issue on the agenda of most countries for many years, but its focus has changed over time. In the 1970s and early 1980s the emphasis was mostly on the proper tax base for corporate taxation. This is exemplified in the Meade Report (1978), which proposed alternative corporate tax base definitions that would prevent the distortive taxation of marginal investments earning no excess return. Since then, the attention of policymakers and academics has shifted to the level of statutory tax rates. As is stressed in the Mirrlees Review (Auerbach et al., 2010), the modern-day analogue to the Meade Report, the main distinguishing feature driving current corporate tax policy is its international dimension, with a particular focus on the internationalization strategies of highly profitable firms.

In this paper we link the development of corporate tax structure to the rise in international trade and increasing economic integration. For this purpose we develop a model of a small open economy which trades different varieties of a good produced under conditions of monopolistic competition with a large rest of the world. ${ }^{1}$ Our model allows for cost heterogeneity of firms both in the small open economy and in the large rest of the world. Importantly, and in contrast to much of the recent literature on international capital taxation (see Fuest et al., 2005, for a survey) we endogenize both the optimal tax rate and the tax base chosen by the small country. Hence the small country has independent instruments to tax the excess profits of heterogeneous firms, and to control aggregate output.

In this setting we show that it is optimal for the small country's government to effectively subsidize capital inputs by granting a tax allowance for the costs of capital in excess of its true value. Economic integration, measured either by a reduction in the unit costs of shipping goods abroad or by a reduction in the fixed costs of serving an export market, reduces the optimal subsidy for marginal investment. This is because rising exports weaken the link between capital subsidies and domestic consumption in

\footnotetext{
${ }^{1}$ Broda and Weinstein (2006) document the increase in the number of traded varieties for the example of the United States. In 1972 the U.S. imported 7,731 goods from 9.7 countries on average, whereas it imported 16,390 goods from 15.8 countries on average in 2001. This corresponds to an increase in the total number of imported varieties (new goods, or goods from new sources) of $250 \%$.
} 
the small country and because economic integration makes it more costly to subsidize domestic investment that crowds out more productive exporters from abroad. Using simulation methods we also show that the reduction in the effective capital subsidy is brought about by a fall in the corporate tax rate, which serves as a multiplier for the implicit subsidization of capital inputs by means of generous depreciation allowances. By incorporating firm heterogeneity we are able to analyze how these changes in tax policy affect firms with different productivities. In particular, we show that the endogenous policy response in our model reinforces the selection effect arising from economic integration, thus strengthening the reallocation of resources towards the most productive firms. As the effective capital subsidy on marginal investment is reduced, this forces low-productivity firms in the small country to exit the market, adding to the effect of stronger foreign competition resulting from a more integrated economy. Similarly there is an additional increase in the number of foreign firms exporting to the small country, as this country's tax discrimination in favor of domestic firms is reduced. These additional effects imply that the well-known productivity improvements brought about by falling trade barriers will be enlarged when tax policy is endogenous.

To compare our results to actual policy developments, Table 1 summarizes key indicators of corporate tax systems in the OECD countries since the mid-1980s. In general, corporate tax reforms have followed a pattern of tax rate cut cum base broadening. ${ }^{2}$ Columns (1) and (2) show the well-known fact that statutory corporate tax rates have fallen very significantly (by roughly a third) during the period 1985-2005, a trend that has further continued in recent years. Columns (3) and (4) demonstrate that, despite this fall in statutory tax rates, corporate tax revenues have risen in most OECD countries. This is indicative of a strong increase in the profitability of the corporate sector during this period. This development is consistent with the aggregate productivity increase in the corporate sector that occurs in our model, as a result of both economic integration and the optimal adjustment of the corporate tax system.

Columns (5)-(8) in Table 1 show the development of effective marginal tax rates (EMTRs), which measure the tax rate on a marginal investment project that earns

\footnotetext{
${ }^{2}$ See Devereux et al. (2002) for a detailed survey of the changes in corporate taxation among the OECD countries since the 1980s. Klemm and van Parys (2009) show that similar trends can be observed in a sample of 40 developing countries in Latin America, the Caribbean and Africa.
} 
Table 1: Corporate taxation in selected OECD countries (1985-2005)

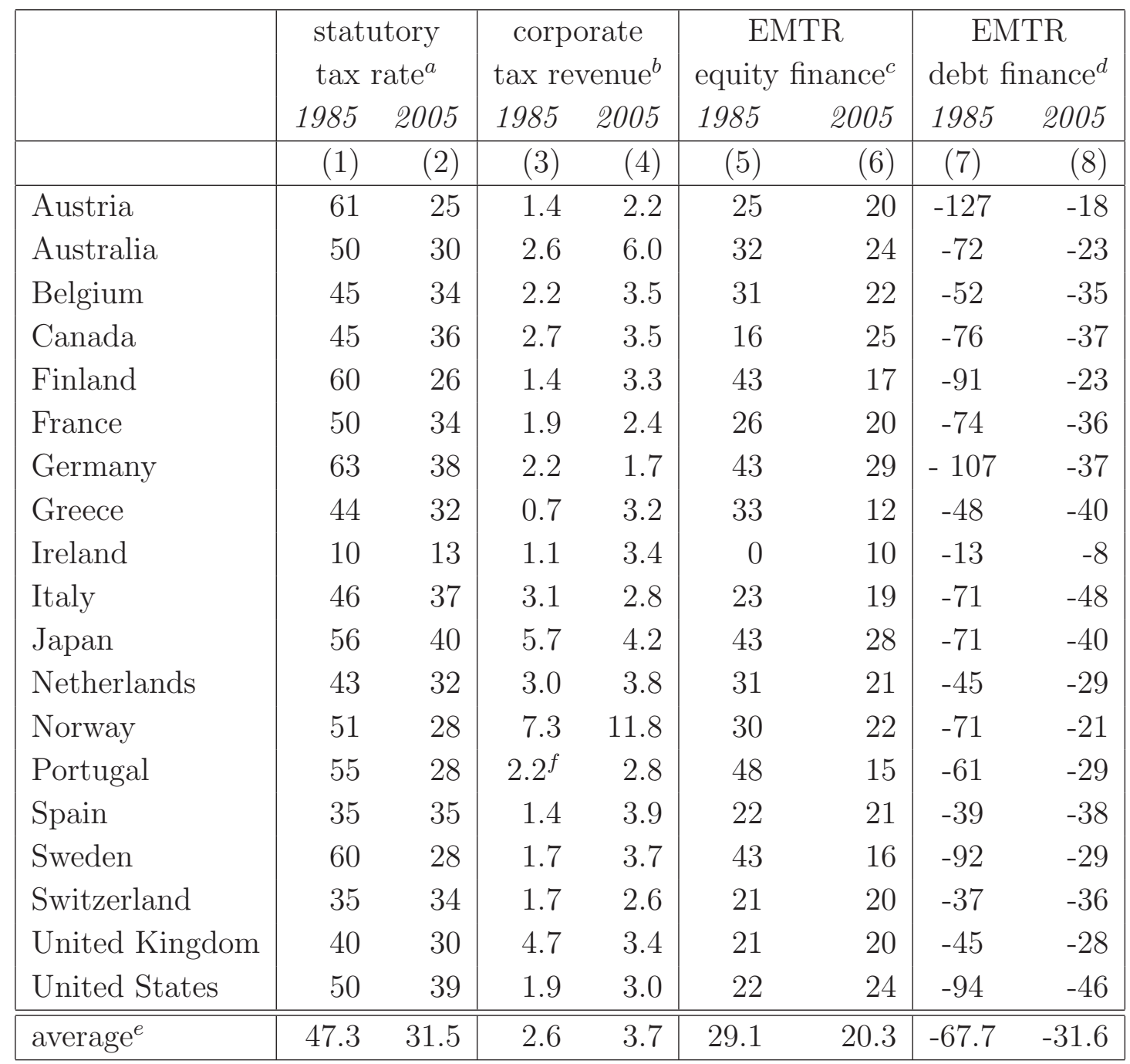

${ }^{a}$ including local taxes

${ }^{b}$ as a percentage of GDP

${ }^{c}$ investment in plant and machinery financed by retained earnings or equity; real discount rate: $10 \%$, inflation rate: $3.5 \%$, depreciation rate: $12.25 \%$

${ }^{d}$ investment in plant and machinery financed by debt; otherwise as in ${ }^{b}$

${ }^{e}$ unweighted average in sample

f 1990

Sources: Devereux et al. (2002); http://www.ifs.org.uk/publications/3210

OECD (2008), Table 12 http://dx.doi.org./10.1787/443744327555 
the competitive rate of return. In contrast to the statutory tax rate, the EMTR also incorporates changes in the tax base and its value depends critically on the assumption of how the marginal investment is financed. Columns (5) and (6) give EMTR calculations when the marginal investment is financed by equity, the costs of which are not deductible from the corporate tax base. In this case EMTRs are generally positive and fall over time. This indicates that, in most countries, changes in effective tax rates have been driven primarily by the development of corporate tax rates. ${ }^{3}$ Columns (7) and (8) show the EMTR calculations when the marginal investment project is instead financed by debt. In this case the cost of financing - the interest paid to the lender - is deductible from the corporate tax base. As the table shows, capital is then effectively subsidized, at the margin, in all OECD countries. ${ }^{4}$ With a negative EMTR, a fall in the statutory tax rate reduces the value of the capital subsidy and this effect is reinforced by a simultaneous broadening of the tax base. This is the reason why the EMTRs on debt-financed investment have risen unanimously and significantly in almost all OECD countries since the mid-1980s.

The results of our model correspond to the development of empirical EMTRs for debtfinanced investments, as given in columns (7)-(8) of Table 1. There are also good reasons to regard debt as the relevant mode of financing for our analysis, because of its taxpreferred status. As the comparison of EMTRs for different modes of financing shows, debt financing is the least-cost way of financing investment when risk considerations are absent. Our analysis can therefore be seen as a benchmark that applies in a world where default risk is limited and marginal investments will mostly be financed by debt. Several empirical indicators suggest that debt finance has played an increasing role in the period covered by Table 1 , prior to the onset of the financial crisis. $^{5}$

\footnotetext{
${ }^{3}$ Notable exceptions to this general trend are Canada and the United States where EMTRs have risen over time, despite the fall in statutory tax rates.

${ }^{4}$ The EMTR is defined as $E M T R=(c o c-r) / c o c$, where $c o c$ is the after-tax cost of capital and $r$ is the competitive interest rate (cf. Devereux et al., 2002, p. 461). As a marginal investment just covers its financing cost, the deduction for the interest cost of debt fully offsets the taxation of the return to investment. In addition, depreciation allowances often exceed true economic depreciation, thus leading to negative values for the EMTR. Moreover, the above definition shows that negative EMTRs can become very high (exceeding 100\% in absolute value) when the cost of capital in the denominator is positive, but small.

${ }^{5}$ One important factor leading to an increased aggregate role of debt finance is the substantial
} 
Our analysis can be linked to several strands in the literature. A small number of papers in the corporate tax literature simultaneously analyzes optimal tax rate and tax base policies in open economies. For example, Haufler and Schjelderup (2000), Fuest and Hemmelgarn (2005) and Devereux et al. (2008) consider different models of income shifting within multinational firms and link this to the observed tax-rate-cutcum-base-broadening patterns of corporate tax reforms. Egger and Raff (2007) analyze, both theoretically and empirically, tax competition via tax rates and tax bases for an internationally mobile monopolist. In contrast to our model, however, the effective marginal tax rate on capital is held constant in their analysis. Moreover, none of these papers incorporates firm heterogeneity.

On the other hand, several papers have analyzed the effects of exogenous trade and tax policies in open economies with heterogeneous firms. Demidova and RodriguezClare (2009) compare the effects of import tariffs and export subsidies on aggregate productivity and welfare in a small open economy. Chor (2009) analyzes the effects of a production subsidy in an economy that competes for foreign direct investment. Closer to our setting, Baldwin and Okubo (2009) study the effects of tax rate and tax base policies on the location of internationally mobile firms. They show that a tax-rate-cutcum-base-broadening reform that keeps the effective tax rate constant for the marginal firm always increases tax revenues. These papers, however, do not endogenize optimal government policies.

Some recent papers derive optimal tax policies in models with heterogeneous firms. Pflüger and Südekum (2009) analyze optimal equilibrium subsidies to market entry in an open economy model of policy competition. Davies and Eckel (2010) analyze tax rate competition for internationally mobile, heterogeneous firms, whereas Krautheim and Schmidt-Eisenlohr (2011) derive Nash equilibrium tax rates when the location of rise in the sectoral share of the banking, finance and insurance industries, which is characterized by very high debt-equity ratios. In the early 1980s this sector was responsible for about $5 \%$ of corporate tax revenues in the United States and for $10 \%$ of corporate tax revenues in the United Kingdom, but this share rose to more than $25 \%$ of corporate tax revenues in both countries in the early $2000 \mathrm{~s}$ (see Auerbach et al., 2010, Figure 9.5, p. 849). Moreover, several indicators point to rising levels of corporate debt in the non-financial sector (see Keen et al., 2010, pp. 45-47). In the Eurozone, for example, the ratio of non-financial corporate debt to GDP rose from around 50\% in 1998 to $66 \%$ in 2006 (European Central Bank, 2006). 
firms is fixed but profits can be shifted between countries. These papers, however, focus solely on tax rate competition and do not endogenize the simultaneous determination of the corporate tax base. Finally, Finke et al. (2010) perform a microsimulation analysis to evaluate the impact of the German 2008 corporate tax reform, which followed a pattern of tax rate cut cum base broadening, on heterogeneous firms. They show that firms with low productivity benefitted least from the reform, because they were hit most by the reduction of depreciation allowances.

The present paper is organized as follows. Section 2 describes the basic model employed in our analysis. Section 3 derives the small country's optimal tax structure. Section 4 analyzes the effects of economic integration on the government's optimal policy response and on the entry and exit decisions of firms with different levels of productivity. Section 5 concludes.

\section{The model}

We study a two-country model of a small open economy (the home country) and a large rest of the world (the foreign country, whose variables are denoted by an asterisk). The focus of our analysis lies on the tax policy in the small home country, whose government chooses an optimal corporate tax structure taking as given the degree of economic integration. The two countries produce and trade two goods, a homogeneous numeraire good $Y$ and a differentiated good $X$. Following Melitz (2003), firms in the differentiated sector $X$ are heterogeneous with respect to their unit production costs. Consumers in the small home country hold a total endowment of $K$ units of capital, which is mobile internationally. Capital is used in the production of both goods.

\subsection{Consumers}

Consumers in home are homogeneous and value the two private goods $X$ and $Y$. The direct utility function is quasi-linear and given by

$$
U \equiv \mu \ln X+Y^{D}, \quad X \equiv\left[\int_{j \in \Omega} q(j)^{\alpha} d j\right]^{\frac{1}{\alpha}} .
$$


In eq. (1), $Y^{D}$ is the quantity consumed of the numéraire good and $X$ is the DixitStiglitz composite of all varieties in the monopolistically competitive sector that are available to home consumers. The set of these varieties is given by $\Omega$, elements of which can include home- and foreign-produced varieties. Varieties are consumed in quantity $q(j)$, where $j$ is the index for the firm producing the variety. Varieties are substitutes and the elasticity of substitution between any two varieties is given by $\varepsilon \equiv 1 /(1-\alpha)>1$, where $\alpha \in(0,1)$.

Utility maximization requires that the ratio of marginal utilities for the two private goods equals their relative price. From the utility function (1) this implies $\mu / X=P$ and thus fixes the expenditures for the differentiated good $X$ at $\mu .{ }^{6}$ This yields isoelastic demand functions for each variety

$$
q(j)=\left[\frac{P}{p(j)}\right]^{\varepsilon} \frac{\mu}{P},
$$

where the price index for good $X$ is

$$
P=\left[\int_{j \in \Omega} p(j)^{-(\varepsilon-1)} d j\right]^{-\frac{1}{\varepsilon-1}} .
$$

Finally, with $\mu$ spent on the differentiated good, the remainder of income $I$ is spent on good $Y$. Income in home is composed of three sources: the return to the fixed capital endowment $K$, the net profits of domestic firms, and tax revenues $R$, which are redistributed to consumers as a lump sum. This implies:

$$
Y^{D}=I-\mu \text {. }
$$

\subsection{Producers}

In the numéraire sector $Y$, one unit of capital is used to produce one unit of output. International trade in the numeraire good then fixes the return to capital at unity. ${ }^{7}$

\footnotetext{
${ }^{6}$ This simplifying result of the quasi-linear preference structure has been exploited by Chor (2009), Cole and Davies (2011), and others.

${ }^{7}$ Since capital is internationally mobile, the two countries can effectively trade capital against good $Y$, implying that our model does not define in which country the numeraire good is produced. This, however, is immaterial for all of our results.
} 
In the differentiated $X$ sector, each country has an exogenous mass of internationally immobile potential entrants ('entrepreneurs'), $N^{e}$ in home and $N^{e *}$ in foreign, who are capable of producing a variety of the differentiated good. We normalize $N^{e} \equiv 1$. Since the home country is small, its policy changes do not affect the mass of active firms in foreign (cf. Flam and Helpman, 1987). ${ }^{8}$ Each entrepreneur receives the residual profit from the firm producing the variety, which then enters into the income of the country where production takes place (in contrast to the return to internationally mobile capital, which accrues in the country where the capital owner resides). Entrepreneur $j$, and thus firm $j$ in the $X$ sector, is exogenously assigned a unit capital requirement $a(j)$. The distribution of these productivities across entrepreneurs is given by $G(.){ }^{9}$ Since firms differ only with respect to their unit costs $a(j)$, in our discussion we will often replace the firm index $j$ with the firm-specific costs $a$.

If a firm decides to produce in the domestic market, it must pay a uniform overhead cost of $F d .{ }^{10}$ In addition, if it chooses to service the export market, it incurs a further fixed cost $F_{x}$ as well as per unit (iceberg) transportation costs. These costs are such that in order for one unit of output to arrive overseas, the firm must produce $1+\tau$ units. Combining this with the unit production requirements results in domestic (subscript $d$ ) and export (subscript $x$ ) capital demands for a firm with input coefficient $a$ of:

$$
k_{d}(a) \equiv a q_{d}(a)+F_{d}, \quad k_{x}(a) \equiv(1+\tau) a q_{x}(a)+F_{x} .
$$

Similarly, revenues of a firm with variable unit costs $a$ in the two markets are:

$$
\rho_{d}(a) \equiv p_{d}(a) q_{d}(a), \quad \rho_{x}(a) \equiv p_{x}(a) q_{x}(a)
$$

In order to write the profit equation, we must first describe the tax system. The government of home determines both the tax rate and the tax base for the profit-making, differentiated sector $X$. Taxable profits are subject to the corporate tax rate $t \in(0,1)$.

\footnotetext{
${ }^{8}$ This definition of 'small' has been applied to the heterogenous firms literature by Demidova and Rodriguez-Clare (2009), among others.

${ }^{9}$ Some heterogeneous firm models, including Melitz (2003), assume instead that entrepreneurs draw from this distribution of productivities at a cost. As discussed by Cole (forthcoming) and Jørgensen and Schröder (2008), however, this approach and ours yield generally comparable results.

${ }^{10}$ This can be interpreted as 'entrepreneurial services' and captures the amount of capital needed for startup.
} 
The base of the corporation tax is given by the firm's revenue less a tax-deductible share $\delta$ of the total capital outlays that are incurred by each firm. Thus $\delta$ incorporates the tax deductibility of the costs of financing the investment and of its real economic depreciation. Recalling that the competitive return to capital is normalized to unity in our framework, the after-tax profits of a firm with costs $a$ in market $i \in\{d, x\}$ are then given by

$$
\pi_{i}(a)=\underbrace{\rho_{i}(a)-k_{i}(a)}_{\text {gross profits }}-t \underbrace{\left[\rho_{i}(a)-\delta k_{i}(a)\right]}_{\text {taxable profit base }} \equiv(1-t) \pi_{i}^{g}
$$

where

$$
\pi_{i}^{g} \equiv \rho_{i}(a)-\Delta(t, \delta) k_{i}(a) \quad \forall i \in\{d, x\}
$$

are the 'gross profits' of a firm ${ }^{11}$ in market $i$ and

$$
\Delta(t, \delta) \equiv 1+\frac{t}{1-t}(1-\delta)
$$

is the tax factor with which the competitive rental rate of capital must be multiplied for all $X$ producers in the home country. Since the rental rate is unity, $\Delta$ equals the (after-tax) cost of capital in our framework, which is in turn directly related to the EMTR (see footnote 4). Equation (9) immediately shows that any given level of $\Delta$ can be obtained from an infinite number of combinations of the government's primary tax parameters $t$ and $\delta$.

Our formulation allows for a simple representation of after-tax profits by regarding the corporate tax as a proportional levy on the difference between revenues $\rho_{i}$ and the total capital cost $\Delta k_{i}$. In the special case where capital costs can be fully deducted from the corporate tax base $(\delta=1)$ the cost of capital is $\Delta=1$ and the corporate tax is a tax on pure profits only. When the tax rate $t$ is positive and the tax deductibility of inputs is incomplete $(\delta<1)$, then the cost of capital is $\Delta>1$ and the corporate tax includes a partial taxation of capital inputs. Conversely, if $t>0$ and $\delta>1$, then the corporation tax implies $\Delta<1$ and hence an effective subsidization of capital inputs. Note that when $\Delta<1$, an increase in $\Delta$ can be achieved by a reduction in the tax

\footnotetext{
${ }^{11}$ Strictly speaking, $\pi_{i}^{g}$ are the profits before deducting the corporate tax rate $t$, but incorporating the tax-inclusive cost of capital $\Delta$. For brevity, though somewhat loosely, we will refer to this term as 'gross profits' in the following.
} 
rate, a base-broadening decrease in $\delta$, or both. In any case, capital market equilibrium will ensure positive values for the cost of capital and thus $\Delta>0$.

Substituting (5) and (6) into (7) and optimizing yields profit-maximizing prices and quantities for each firm in the domestic market:

$$
p_{d}(a)=\frac{\Delta a}{\alpha}, \quad q_{d}(a)=\left[\frac{\alpha}{\Delta a}\right]^{\varepsilon} P^{\varepsilon-1} \mu .
$$

This shows that more productive firms (firms with a lower $a$ ) charge lower prices and sell larger quantities. Also an increase in the cost of capital $\Delta$ raises prices and reduces quantities. For future discussion, note that this reduction in output is greater for highproductivity firms (i.e. those with low values of $a$ ).

Similarly, firm-specific prices and quantities in the export market are given by

$$
p_{x}(a)=\frac{(1+\tau) \Delta a}{\alpha}, \quad q_{x}(a)=\left[\frac{\alpha}{\Delta(1+\tau) a}\right]^{\varepsilon}\left(P^{*}\right)^{\varepsilon-1} \mu^{*},
$$

where $P^{*}$ is the aggregate price index in foreign and $\mu^{*}$ is foreign's expenditure share for good $X$. These parameters are fixed from the perspective of the small home country. Note also that, as a result of transport costs, export prices are higher and export quantities are lower for any given level of $a$ than in the domestic market.

These choices give maximized after-tax profits in the domestic market equal to

$$
\pi_{d}(a)=(1-t)\left\{(1-\alpha)\left(\frac{\alpha P}{\Delta a}\right)^{\varepsilon-1} \mu-\Delta F_{d}\right\},
$$

indicating that more productive firms earn larger profits. Moreover, since $\varepsilon>1$, profits are unambiguously falling in the cost of capital parameter $\Delta$.

Comparably, the additional after-tax profits for an exporting firm equal

$$
\pi_{x}(a)=(1-t)\left\{(1-\alpha)\left[\frac{\alpha P^{*}}{(1+\tau) \Delta a}\right]^{\varepsilon-1} \mu^{*}-\Delta F_{x}\right\} .
$$

Finally, we assume that the foreign firms in the monopolistically competitive sector face the same distribution of costs. Ignoring taxes in foreign (i.e. assuming $t^{*}=0$ and $\Delta^{*}=1$ ), the maximized profits of a foreign firm that also chooses to export to the home country are given by ${ }^{12}$

$$
\pi_{x}^{*}(a)=(1-\alpha)\left[\frac{\alpha P}{\left(1+\tau^{*}\right) a}\right]^{\varepsilon-1} \mu-F_{x}^{*} .
$$

\footnotetext{
${ }^{12}$ Note that the assumptions on $t^{*}$ and $\Delta^{*}$ are not necessary, but are made simply to reduce notation.
} 


\subsection{Equilibrium}

Market Entry Decisions: The home country's firms will only be active in the domestic market if $\pi_{d}(a) \geq 0$ holds. Setting $\pi_{d}(a)=0$ in equation (12) determines a cutoff productivity (or a maximum cost threshold) $a_{d}$, given by

$$
a_{d} \equiv \alpha P \Delta^{-\frac{\varepsilon}{\varepsilon-1}}\left(\frac{\mu}{\varepsilon F_{d}}\right)^{\frac{1}{\varepsilon-1}}
$$

All firms with unit costs $a \leq a_{d}$ will choose to be active in the domestic market. An increase in the cost of capital $\Delta$ reduces the cutoff value $a_{d}$, implying that fewer firms enter home's market. This result holds even when we account for the general equilibrium impact on $P$ (see Appendix A).

With the exogenous mass of firms normalized to $N^{e}=1$, the number of domestic firms operating in home's market is then given by $N=G\left(a_{d}\right)<1$, where $G\left(a_{d}\right)$ is the value of the cumulative distribution function at the cutoff level of costs.

Similarly, domestic firms choose to export if $\pi_{x}(a) \geq 0$ in (13). This yields a maximum cost threshold $a_{x}$ for exporting:

$$
a_{x} \equiv \frac{\alpha P^{*}}{1+\tau} \Delta^{-\frac{\varepsilon}{\varepsilon-1}}\left(\frac{\mu^{*}}{\varepsilon F_{x}}\right)^{\frac{1}{\varepsilon-1}} .
$$

All firms with unit costs $a \leq a_{x}$ will choose to export. Since any firm choosing to export must pay $F_{d}$ as well as $F_{x}$, all exporting firms will also serve the domestic market. However, not all firms selling in the domestic market will be able to cover the additional costs of exporting. This implies that $a_{d}>a_{x}$.

Finally, foreign firms choose to export if $\pi_{x}^{*}(a)>0$ holds in (14). This yields a cutoff cost level for foreign producers $a_{x}^{*}$ equal to

$$
a_{x}^{*} \equiv \frac{\alpha P}{1+\tau^{*}}\left(\frac{\mu^{*}}{\varepsilon F_{x}^{*}}\right)^{\frac{1}{\varepsilon-1}} .
$$

The foreign export cutoff, and hence the number of foreign exporters $M^{*}=G\left(a_{x}^{*}\right)$, are only affected through the domestic price index $P$. The total number of active firms in the rest of the world, $N^{*}$, is exogenous in our model by the small country assumption. Note that, by the foreign equivalent of (15), this implies that $P^{*}$ is fixed. 
Capital Market Clearing: For the purpose of aggregation, we denote the total capital demand of a firm serving both the domestic and the export market by $k(a) \equiv$ $k_{d}(a)+k_{x}(a)$. Similarly, total sales revenue is $\rho(a) \equiv \rho_{d}(a)+\rho_{x}(a)$ and total profits are $\pi(a) \equiv \pi_{d}(a)+\pi_{x}(a)$.

Capital market clearing is then derived as follows. In the home country, the total demand for capital in the $Y$ and $X$ sectors is given by ${ }^{13}$

$$
K_{Y}=Y^{S}, \quad K_{X} \equiv \int_{0}^{a_{d}} k(a) d G(a)
$$

where $Y^{S}$ stands for the production of good $Y$. Any discrepancy between home's capital endowment $K$ and its total capital demand $K_{Y}+K_{X}$ is met by international trade in capital.

Tax Revenues: Tax revenues $R$ are determined as the difference between the firms' gross value added and their net profits. Using $\pi_{i}^{g}$ from (8) gives

$$
\begin{aligned}
R= & \int_{0}^{a_{d}}[\rho(a)-k(a)] d G(a)-(1-t) \int_{0}^{a_{d}} \pi^{g}(a) d G(a) \\
& =t \int_{0}^{a_{d}} \pi^{g}(a) d G(a)+(\Delta-1) \int_{0}^{a_{d}} k(a) d G(a) .
\end{aligned}
$$

Intuitively, tax revenue can be decomposed into a profit tax on the base $\pi^{g}$ and a tax on capital inputs levied at the rate $(\Delta-1)$. The first of these terms cancels against the reduction in profit income that is caused by the corporation tax, reflecting the fact that any simultaneous change in the government's tax parameters $t$ and $\delta$ that holds $\Delta$ constant represents a lump-sum tax reform.

We assume that tax revenues are redistributed to consumers in a lump-sum fashion. Note that this assumption is not restrictive in the present framework, and it yields the same resource allocation as if we required a fixed (and feasible) level of revenues and public good supply. This is because only the effective tax rate $(1-1 / \Delta)$ matters for resource allocation and the home country has two instruments in our model in order to achieve any desired level of the EMTR. As a result, by raising the corporate tax rate and simultaneously increasing the tax deductibility of capital expenditures to keep the

\footnotetext{
${ }^{13}$ Recall that $a_{d}>a_{x}$. Hence aggregating over the capital demands of all firms with cost levels up to $a_{d}$ includes the capital demands for exports of all firms that serve both markets.
} 
EMTR constant, the home country is able to increase the taxation of inframarginal profits and therefore to raise tax revenues in a lump-sum way. We will further discuss this property of our model below.

Income: Recall that income is the sum of tax revenues, the return on the fixed endowment of capital $K$, and the after-tax profits of domestic firms, Hence we can express income of the representative consumer as

$$
I \equiv K+(1-t)\left[\int_{0}^{a_{d}} \pi(a) d G(a)\right]+R .
$$

or by including the level of tax revenues:

$$
I=K+\int_{0}^{a_{d}} \pi^{g}(a) d G(a)+(\Delta-1) \int_{0}^{a_{d}} k(a) d G(a) .
$$

The Price Level: The cutoff levels in (15) and (17) include the domestic price level $P$, which is endogenous. To derive a first expression for $P$, we define harmonic means of the marginal costs of domestic producers and of foreign exporters:

$$
\tilde{a}_{d}\left(a_{d}\right) \equiv\left[\int_{0}^{a_{d}} a^{-(\varepsilon-1)} d G(a)\right]^{-\frac{1}{\varepsilon-1}}, \quad \tilde{a}_{x}^{*}\left(a_{x}^{*}\right) \equiv\left[\int_{0}^{a_{x}^{*}} a^{-(\varepsilon-1)} d G(a)\right]^{-\frac{1}{\varepsilon-1}} .
$$

We can then apply the mark-up pricing rules in (10) and (11) to these harmonic means to obtain

$$
P^{-(\varepsilon-1)}=\left(\frac{\Delta \tilde{a}_{d}}{\alpha}\right)^{-(\varepsilon-1)}+\left[\frac{\left(1+\tau^{*}\right) \tilde{a}_{x}^{*}}{\alpha}\right]^{-(\varepsilon-1)} .
$$

\section{The optimal tax structure}

The home government chooses its capital tax structure so as to maximize the utility of the representative consumer. Using (19) and (4) in (1) yields indirect utility

$$
V=\int_{0}^{a_{d}} \pi^{g}(a) d G(a)+(\Delta-1) \int_{0}^{a_{d}} k(a) d G(a)-\mu \ln P+C,
$$

where $C \equiv K-\mu+\mu \ln \mu$ is a constant.

The cost of capital $\Delta$, which incorporates the effective taxation of capital inputs, is the government's critical choice parameter in our model. Differentiating (21) with respect to $\Delta$ yields the first-order condition

$$
\frac{\partial}{\partial \Delta} \int_{0}^{a_{d}} \pi^{g} d G+\int_{0}^{a_{d}} k(a) d G+(\Delta-1) \frac{\partial}{\partial \Delta} \int_{0}^{a_{d}} k(a) d G-\frac{\mu}{P} \frac{\partial P}{\partial \Delta}=0 .
$$


It is shown in Appendix A that this can be simplified to

$$
\frac{\mu}{P} \frac{\partial P}{\partial \Delta}\left\{\int_{0}^{a_{d}} \alpha\left[\frac{q_{d}(a) P}{\mu}\right]^{\frac{\varepsilon-1}{\varepsilon}} d G-1\right\}+(\Delta-1) \frac{\partial}{\partial \Delta} \int_{0}^{a_{d}} k(a) d G=0 .
$$

Appendix A further shows that the first term in (22) is strictly negative. A rise in $\Delta$ raises the input costs of all firms and this is passed on via mark-up pricing into the price level (20). Note that, due to the markup arising from firms' market power, the price level rises by more than the cost of capital. Other things equal, this increase in the price level raises producer profits. The positive effect on the income of the representative consumer is insufficient, however, to compensate the consumer for the loss in purchasing power resulting from the increase in $P$. Intuitively this is because a tax-induced increase in the cost of capital aggravates the distortion arising from imperfect competition in the differentiated sector and further contributes to the underconsumption of good $X$.

In an interior optimum for $\Delta$, the second effect in (22) must therefore be positive. The aggregate change in the demand for capital in this term is unambiguously negative. Intuitively an increase in the cost of capital $\Delta$ reduces the cutoff levels of costs $a_{d}$ and $a_{x}$ at which firms can profitably enter the domestic and the foreign market [see eqs. (15) and (16)]. Hence the mass of active firms falls both in the domestic market and in the exporting market. At the same time, all firms that remain active reduce their output, lowering their variable demand for capital [see eqs. (5) and (10)-(11)]. It is shown in the appendix that these negative effects on the demand for capital cannot be overcompensated by the rise in the price level (and thus firm profitability) that accompanies the increase in $\Delta$. It thus follows that $(\Delta-1)$ must be unambiguously negative in an interior tax optimum. This is summarized in:

Proposition 1 The optimal policy in the small open economy is to set $\Delta<1$, implying that capital inputs are effectively subsidized. For a positive corporate tax rate $t>0$, the tax allowance for capital inputs thus exceeds their true costs $(\delta>1)$ and the tax base is narrower than under a pure profit tax.

\section{Proof: See Appendix A.}

From Proposition 1 the optimal policy for the small country is to grant a capital subsidy to all active domestic firms. This reduces the price level of good $X$ and increases 
consumption, thus offsetting the initial distortion arising from monopolistic competition in this sector. As in homogeneous firms models the capital subsidy increases the variable capital demand, and hence output, for all active firms. Additional effects arise from firm heterogeneity. Thus the subsidization of capital for home producers leads to additional entry of domestic firms into both the home and the foreign markets, whereas the number of foreign exporters to the home market falls. These effects are discussed further in Section 4.2.

To provide a more detailed analysis of the first-order condition (22), we now introduce the assumption that the unit costs of firms follow the Pareto distribution ${ }^{14}$

$$
G(a)=\left(\frac{a}{a_{0}}\right)^{\theta}, \quad 0<a \leq a_{0}, \quad \theta>\varepsilon-1 .
$$

The Pareto distribution is characterized by two parameters, the maximum cost level $a_{0}$ and the exponent $\theta$. The larger is $\theta$ the more firms draw high cost levels approaching $a_{0}$, and hence the lower is the cost heterogeneity between the different firms.

In a first step, Appendix B derives reduced-form expressions for the four principal endogenous variables in our analysis, the three cost thresholds $a_{d}, a_{x}$ and $a_{x}^{*}$ and the aggregate price level $P$ [see eqs. (B.2)-(B.5)]. For later use, we summarize the comparative static properties of these variables with respect to $\Delta$ :

$$
\frac{\partial P}{\partial \Delta}>0, \quad \frac{\partial a_{d}}{\partial \Delta}<0, \quad \frac{\partial a_{x}^{*}}{\partial \Delta}>0, \quad \frac{\partial a_{x}}{\partial \Delta}<0 .
$$

The next step is to obtain a compact first-order condition for $\Delta$ based on the Pareto distribution. The resulting optimality condition derived in Appendix $B$ is:

$$
\frac{1}{\Delta}\left[\frac{\theta-(\varepsilon-1)}{\varepsilon \theta}+\alpha-\Delta\right]\left[\Gamma(\Delta)+\frac{\varepsilon \theta}{\varepsilon-1} \chi(\Delta)\right]+\chi(\Delta)=\frac{\theta-(\varepsilon-1)}{\theta(\varepsilon-1)}
$$

where

$$
\chi(\Delta) \equiv \frac{F_{x} G\left(a_{x}\right)}{F_{d} G\left(a_{d}\right)}=\left(\frac{1}{1+\tau}\right)^{\theta} \frac{N^{*}\left[\Delta^{-\left(\varepsilon \frac{\theta}{\varepsilon-1}-1\right)}+\left(\frac{1}{1+\tau^{*}}\right)^{\theta}\left(\frac{F_{d}}{F_{x}^{*}}\right)^{\frac{\theta}{\varepsilon-1}-1}\right]}{\left(\frac{F_{x}}{F_{d}^{*}}\right)^{\frac{\theta}{\varepsilon-1}-1}\left(1-\frac{\varepsilon-1}{\theta}\right)\left(\frac{\mu}{\varepsilon F_{d}^{*}}\right)} \geq 0
$$

${ }^{14}$ This distribution is frequently used in the literature on firm heterogeneity (e.g. Baldwin and Okubo, 2009; Krautheim and Schmidt-Eisenlohr, 2011), as the Pareto distribution is analytically convenient and it is also a good approximation of empirically observed cost distributions. 
gives the aggregated fixed costs incurred by home exporting firms, relative to the aggregated fixed costs of all domestic firms, and

$$
\Gamma\left(\Delta ; \tau^{*}, F_{d} / F_{x}^{*}\right) \equiv\left[1+\frac{\left(\frac{\varepsilon \theta}{\varepsilon-1}-1\right) \Delta^{\varepsilon \frac{\theta}{\varepsilon-1}-1}\left(\frac{1}{1+\tau^{*}}\right)^{\theta}\left(\frac{F_{d}}{F_{x}^{*}}\right)^{\frac{\theta}{\varepsilon-1}-1}}{1+\Delta^{\frac{\theta}{\varepsilon-1}-1}\left(\frac{1}{1+\tau^{*}}\right)^{\theta}\left(\frac{F_{d}}{F_{x}^{*}}\right)^{\frac{\theta}{\varepsilon-1}-1}}\right] \geq 1
$$

is a measure of the relative fixed costs incurred by domestic vis-à-vis foreign (exporting) firms for serving the domestic market.

To interpret the first-order condition (25) more closely, we can state the following properties of $\chi(\Delta)$ and $\Gamma(\Delta)$ for special cases where either the import or the export channel of trade in good $X$ is shut down. In our setting this will arise when either the fixed costs of foreign firms to export into the domestic market or the fixed costs of domestic firms to export to the foreign market become prohibitively high, implying $F_{x}^{*} \rightarrow \infty$ and $F_{x} \rightarrow \infty$ respectively. In these cases we get:

$$
\begin{aligned}
& \text { (no exports of } X) \quad \lim _{F_{x} \rightarrow \infty} \quad \chi(\Delta)=0 \\
& \text { (no imports of } X \text { ) } \lim _{F_{x}^{*} \rightarrow \infty} \Gamma(\Delta)=1 \\
& \text { (autarky in } X \text { ) } \quad \lim _{F_{x} \rightarrow \infty} \quad \chi(\Delta)=0 \quad \text { and } \lim _{F_{x}^{*} \rightarrow \infty} \Gamma(\Delta)=1 .
\end{aligned}
$$

For the case of autarky, substituting $\chi=0$ and $\Gamma=1$ in (25) yields, after some manipulations

$$
\Delta^{a u t}=\alpha \equiv \frac{(\varepsilon-1)}{\varepsilon}<1 .
$$

Equation (29) is a special case of the more general result in Proposition 1. It shows that, for the case of autarky, the optimal capital subsidy is higher (i.e., $\Delta$ is lower), when there is weak competition between different varieties of the differentiated good (i.e., $\varepsilon$ is low). Weak competition implies a high mark-up $1 / \alpha$ that each producer charges on its marginal cost. As eq. (10) shows, the optimal capital subsidy in (29) leads to output prices that equal before-tax input prices for each variety of good $X$. Hence the capital subsidy exactly offsets the effects of monopolistic market power. For the case of autarky, the rule (29) therefore guarantees a first-best allocation in our model. 


\section{Trade liberalization}

\subsection{Optimal policy response}

In this section we analyze the optimal adjustment in the effective taxation of capital as implied by $\Delta$, when the home and foreign countries become more closely integrated. As a first step in this analysis, we consider the discrete switch from a situation without any trade in good $X$ to the opening up of either imports or exports. The results for this case are summarized in our next proposition.

Proposition 2 Consider a closed economy that opens up for imports, exports, or both. Starting from the autarky solution $\Delta=\alpha$, the optimal policy response to the opening of trade is to reduce the effective subsidization of capital inputs and raise the cost of capital to $\Delta>\alpha$.

Proof: See Appendix C.

While the formal proof of Proposition 2 is relegated to the appendix, its essence can easily be deduced from inspection of (25). The opening to trade raises the value of $\chi$ above zero and the value of $\Gamma$ above unity. Both of these effects tend to increase the left-hand side of (25), whereas the right-hand side of the equation stays constant. To offset this change, $\Delta$ must rise in equilibrium, thus reducing the value of the first bracketed term on the LHS of (25) (which always remains positive in equilibrium).

To provide an intuitive understanding of Proposition 2, recall that the motivation for the government to grant capital subsidies is to increase domestic consumption of good $X$ and thus counteract the distortion arising from imperfect competition in that sector. The capital subsidy, however, cannot distinguish between firms nor the destination of their output. When some of domestic production is exported, the case for subsidizing capital is weakened, other things being equal, as the production subsidy now partially benefits foreign consumers. In addition, as is well known in heterogenous firms models, there is also a selection effect brought about by heterogeneity. By offering a capital subsidy, the home government encourages additional firms to export even though their productivity is insufficient for that to be profitable in the absence of the subsidy. Since the only gain to the home country from having these firms export is the profits they 
earn, the net impact of these firms' exporting on home income is negative. Hence, when the economy opens up for exports, the home government reduces its capital subsidy (i.e. it raises $\Delta$ ) in order to minimize this loss.

Turning to the import side, heterogeneity again plays a key role. First, recall that since foreign firms are not eligible for the capital subsidy, the subsidy distorts international trade and drives out some foreign exporters by decreasing the domestic price level [eq. (24)]. Since exporters are more productive than the average firm, this means that low-cost imports are being replaced by high-cost domestic production. Thus, the subsidy undermines the welfare improving selection effect discussed by Melitz (2003) and others. Therefore, the switch from autarky to trade causes the small country's government to consider the adverse consequences of capital subsidies for average productivity and leads to a reduction in the optimal capital subsidy.

So far, we have only dealt with a discrete switch from autarky to a situation with trade in the differentiated good. Our next result shows that similar results apply for continuous changes in economic integration, starting from an initial equilibrium with trade in good $X$. There are two different measures of economic integration in our model, the per-unit trade costs $\left(\tau, \tau^{*}\right)$, and the fixed costs of serving an export market $\left(F_{x}, F_{x}^{*}\right)$. The results in the following proposition hold for both of these indicators.

Proposition 3 (a) Consider a situation where the home country imports good $X$, but does not export it. Then either a small reduction in the trade costs $\tau^{*}$ or a reduction in the fixed exporting costs $F_{x}^{*}$ faced by foreign firms leads the home country's government to raise the cost of capital $\Delta$.

(b) Consider a situation with bilateral trade in good $X$. Then either a small reduction in the trade costs $\tau$ or a reduction in the fixed exporting costs $F_{x}$ faced by domestic exporters leads the home country's government to raise $\Delta$.

Proof: See Appendix D.

The fundamental effects behind Proposition 3 are the same as those discussed above. An increase in either exports or imports of the differentiated good, caused by a reduction in unit trade costs or in the fixed costs of serving an export market, will weaken the link between domestic production and domestic consumption and therefore reduces the 
incentive for the home government to subsidize domestic capital inputs. As discussed in the next section, these effects are strengthened by the selection effects caused by firm heterogeneity.

Proposition 3 implies that the subsidization of capital inputs should be continuously reduced, and the cost of capital be accordingly increased, as economic integration proceeds. One way to bring about this increase in the cost of capital (or in the EMTR) is through a broadening of the tax base, i.e. a reduction in the tax deductibility parameter $\delta$, while holding the corporate tax rate constant. Alternatively, the increase in $\Delta$ can be achieved by reducing the corporate tax rate while keeping the tax base parameter $\delta$ constant at a level above unity. From equation (9) the corporate tax rate acts as a multiplier for any given value of the depreciation parameter in excess of true economic costs. Hence an isolated fall in tax rates will raise the cost of capital $\Delta$, other things being equal, while still maintaining a capital subsidy at the margin (i.e. keeping $\Delta$ below unity).

Comparing these alternative patterns with the developments in corporate taxation summarized in Table 1, the second explanation seems to be more relevant from an empirical perspective. As is shown in columns (7)-(8) of Table 1, the EMTR for debtfinanced investments closely mirrors the results summarized in Propositions 1 and 3. Given the rising share of corporate debt finance over the past decades, this financing mode is also very likely to have played an important role for corporate investment in the time period under consideration here. ${ }^{15}$

\subsection{Effects at the firm level}

In this subsection, we delve deeper into the differing firm-level effects from falling trade barriers with a particular eye towards how these effects interact with changes in the optimal policy. As highlighted in Melitz (2003) and others, one of the primary innovations of firm heterogeneity is that falling trade barriers lead to a selection effect

\footnotetext{
${ }^{15}$ The preference for debt finance is most explicit under the 'neutrality view' of corporate financial policy, according to which firms exclusively choose the least-cost source of finance. This is debt finance in most countries, due to its tax-preferred status. See Sørensen (1995) for a survey of different views of the corporate income tax.
} 
that shifts resources towards relatively more productive firms. Therefore it is important to understand how endogenous tax policy also results in selection effects that encourage production by low-cost firms relative to their higher-cost competitors.

In our model, the changes in productivity cutoffs in response to falling trade barriers occur both through direct effects as well as indirect ones which arise through the endogenous policy response. While the direct effects have been widely discussed elsewhere, this is not the case for the indirect ones. These indirect effects can have important implications for the mass of firms in operation as well as average productivity.

In the following we confine ourselves to changes in variable trade costs. It is straightforward, however, to establish that reductions in the fixed beachhead costs of exporters, $F_{x}$ and $F_{x}^{*}$, have qualitatively very similar effects as the variable cost reductions studied here. Moreover, our analysis conceptually separates between the variable trade costs faced by domestic and foreign firms, respectively. Starting with the latter and turning first to the productivity of the last operating domestic firm, we see that:

$$
\frac{d a_{d}}{d \tau^{*}}=\underbrace{\frac{\partial a_{d}}{\partial \tau^{*}}}_{(+)}+\underbrace{\frac{\partial a_{d}}{\partial \Delta}}_{(-)} \underbrace{\frac{d \Delta}{d \tau^{*}}}_{(-)}>0,
$$

where the first term is the direct effect and the second term is the indirect effect through the induced change in the cost of capital $\Delta$. As can be verified from eq. (B.3) in the appendix, the direct effect is positive as a decline in trade cost leads to increased competition by foreign firms. This reduces variable profits for the least productive home firms below the fixed cost of production. In addition, however, it is necessary to consider the indirect effect. By Proposition 3 a fall in trade costs results in an increase in the cost of capital $\Delta$. From eq. (24) this increase in $\Delta$ further reduces the cost cutoff for domestic firms. Therefore the direct effect of trade liberalization is reinforced by the policy response, leading to a greater reduction in $a_{d}$ than would occur if policy were exogenous. This in turn implies that the increase in the average productivity of domestic firms to a reduction in trade costs will be greater when the home country's policy adjusts.

Turning to a decline in home trade costs $\tau$, the effect on the cutoff cost level $a_{d}$ is:

$$
\frac{d a_{d}}{d \tau}=\underbrace{\frac{\partial a_{d}}{\partial \tau}}_{(0)}+\underbrace{\frac{\partial a_{d}}{\partial \Delta}}_{(-)} \underbrace{\frac{d \Delta}{d \tau}}_{(-)}>0 .
$$


In contrast to the change in the foreign trade cost, there is no direct effect on home domestic activity from the home export cost since the cutoff $a_{d}$ is for a firm that does not export. However, there remains an indirect effect. As before, the induced change in tax policy increases the cost of capital, thereby driving low-productivity domestic firms from the market.

In many situations economic integration will simultaneously reduce the trade costs for home and foreign firms, thus combining the effects in eqs. (30) and (31). ${ }^{16}$ Clearly, both effects work in the same direction so that the change in the cutoff level of domestic firms will be even larger when trade costs fall for domestic and foreign firms alike. Importantly, the indirect effects through the induced change in $\Delta$ also mutually reinforce each other, strengthening the selection effect that is caused by trade integration.

Similarly, we can analyze the effects of trade integration on the cutoff cost level of foreign exporters, $a_{x}^{*}$. Again beginning with $\tau^{*}$, we see a comparable reinforcement of the direct effect through the induced policy change:

$$
\frac{d a_{x}^{*}}{d \tau^{*}}=\underbrace{\frac{\partial a_{x}^{*}}{\partial \tau^{*}}}_{(-)}+\underbrace{\frac{\partial a_{x}^{*}}{\partial \Delta}}_{(+)} \underbrace{\frac{d \Delta}{d \tau^{*}}}_{(-)}<0 .
$$

The direct effect of trade integration is now negative, as a decline in $\tau^{*}$ increases profits for the marginal foreign exporter. This leads to additional entry by foreign firms into the home market [see eq. (B.4) in the appendix]. As before, this direct effect is reinforced by the tax policy response. The induced increase in the cost of capital for domestic firms encourages exports by foreign firms [cf. eq. (24)]. Thus, in comparison to a setting in which the home country's tax policy is static, the increased penetration by foreign firms following a drop in trade barriers will be larger when policy is endogenously chosen.

For the effect of domestic trade costs on the cutoff level $a_{x}^{*}$ we get

$$
\frac{d a_{x}^{*}}{d \tau}=\underbrace{\frac{\partial a_{x}^{*}}{\partial \tau}}_{(0)}+\underbrace{\frac{\partial a_{x}^{*}}{\partial \Delta}}_{(+)} \underbrace{\frac{d \Delta}{d \tau}}_{(-)}<0 .
$$

As in eq. (31), there is no direct impact on foreign exporters from a change in the trade costs for home firms. However, there are still the indirect effects as the government

\footnotetext{
${ }^{16}$ For example, trade in either direction would be eased by improvement of transport infrastructures, easier international communication, or mutual trade concessions.
} 
raises $\Delta$ in response to the decline in trade barriers. As discussed above, this indirect effect increases capital costs to home firms, thereby increasing $a_{x}^{*}$. Combining (32) and (33), it is again the case that simultaneous declines in bilateral trade barriers (i.e. in both $\tau$ and $\tau^{*}$ ) work to reinforce one another. Hence trade integration unambiguously increases the number of foreign exporters to the small home country, and the direct effect of trade integration is reinforced by the effects of endogenous policy.

Finally, we consider the impact on the cutoff of home country's exporters. The effects of a decline in the variable trade costs faced by foreign firms are:

$$
\frac{d a_{x}}{d \tau^{*}}=\underbrace{\frac{\partial a_{x}}{\partial \tau^{*}}}_{(0)}+\underbrace{\frac{\partial a_{x}}{\partial \Delta}}_{(-)} \underbrace{\frac{d \Delta}{d \tau^{*}}}_{(-)}>0 .
$$

The direct effect is zero, since the relevant trade costs for home exporters face are given by $\tau$, rather than $\tau^{*}$ [see eq. (B.5)]. With endogenous policy, however, there remains an indirect effect. The induced increase in the cost of capital reduces the profits from exporting. As shown in (24), this increase in $\Delta$ reduces $a_{x}$ and leads low-productivity home exporters to quit the foreign market.

In contrast, the effect of an increase in home's trade costs on home's exporting behavior is not clear cut:

$$
\frac{d a_{x}}{d \tau}=\underbrace{\frac{\partial a_{x}}{\partial \tau}}_{(-)}+\underbrace{\frac{\partial a_{x}}{\partial \Delta}}_{(-)} \underbrace{\frac{d \Delta}{d \tau}}_{(-)} \lessgtr 0 .
$$

The direct effect of a fall in trade costs is to increase the number of home exporters since the reduction in trade costs makes exporting more profitable. The indirect effect, however, works in the opposite direction as the decline in home trade costs raises the cost of capital for home exporters. Hence the direct effect of the fall in foreign trade costs is here mitigated by the indirect policy effect.

In general, therefore, the endogenous policy response may reinforce or counteract the selection effects at the firm level that arise from trade integration. In the small country's home market, however, the effects are unambiguous and summarized in our final proposition.

Proposition 4 A reduction in either $\tau$ or $\tau^{*}$ reduces the threshold level for domestic firms $a_{d}$ and increases the threshold level for foreign exporters $a_{x}^{*}$. Hence the number of 
domestic producers falls, whereas the number of foreign exporters rises. In both cases, the selection effects caused by economic integration are unambiguously strengthened by the endogenous policy adjustment in the domestic cost of capital.

To conclude the analysis, Table 2 summarizes the results of some representative simulations of our model. In these simulations we introduce different levels of government revenue that must be collected from the corporation tax. ${ }^{17}$ The upper panel shows the optimal tax structure for a low revenue requirement $\bar{R}=0.08$, whereas the lower panel gives the optimal tax structure for a high revenue requirement $\bar{R}=0.20 .{ }^{18}$ Comparing the results for these two different cases shows how the corporate tax structure adjusts to bring about the required change in tax revenue. In particular, a higher revenue requirement is met by a higher statutory tax rate and thus by an increased taxation of inframarginal profits. Since the depreciation parameter $\delta$ exceeds unity, implying a capital subsidy at the margin, the higher tax rate can be accompanied by a narrowing of the tax base (a fall in $\delta$ ) while keeping the cost of capital $\Delta$ constant. As we have argued above, the cost of capital $\Delta$ is unaffected by the required amount of tax revenue collections. Moreover since the allocation of firms and the price level depend only on the cost of capital $\Delta$, they are also unaffected by the change in the tax revenue requirement. These values are therefore not reproduced in the lower part of the table. Turning to the effects of economic integration, we separately consider reductions in foreign trade costs $\tau^{*}$ and in domestic trade costs $\tau$. Table 2 shows that reductions in the corporate tax rate are the primary channel through which economic integration increases the cost of capital. The effect on the tax base parameter $\delta$ is typically small and it is not unambiguous, i.e. $\delta$ may either rise (for reductions in $\tau$ ) or it may fall (for a reduction in $\tau^{*}$ in the lower panel). It is also seen that isolated reductions in the home trade $\operatorname{costs} \tau$ raise the home country's tax base (i.e. aggregate gross profits), whereas isolated reductions in $\tau^{*}$ lower the home country's tax base. This is the reason why a fall in $\tau$ permits a stronger cut in the home country's statutory tax rate as compared to a fall in $\tau^{*}$.

\footnotetext{
${ }^{17}$ Note that because the revenue target is fixed, the simulations are not intended to mirror the simultaneous decline in tax rates and rise in revenues found in Table 1.

${ }^{18}$ This corresponds to tax revenue levels making up $10 \%$ and $25 \%$, respectively, of the expenditures for the differentiated good.
} 
Table 2: Simulation results for alternative government revenue requirements

\begin{tabular}{|c|c|cc|cc|c|}
\hline & \multicolumn{5}{|c|}{ revenue requirement $\bar{R}=0.08$} \\
\hline & $\tau^{*}=0.5$ & $\tau^{*}=0$ & \multicolumn{2}{c|}{$\tau=0$} & $\tau^{*}=0$ \\
\hline & $\tau=0.5$ & $\tau=0.5$ & $\tau=0.2$ & $\tau^{*}=0.5$ & $\tau^{*}=0.2$ & $\tau=0$ \\
\hline $\mathrm{t}$ & 0.703 & 0.666 & 0.499 & 0.416 & 0.401 & 0.385 \\
$\delta$ & 1.064 & 1.069 & 1.105 & 1.131 & 1.131 & 1.131 \\
$\Delta$ & 0.849 & 0.862 & 0.895 & 0.907 & 0.912 & 0.918 \\
$P$ & 0.767 & 0.697 & 0.722 & 0.830 & 0.785 & 0.738 \\
$\int \pi^{g}$ & 0.478 & 0.429 & 0.544 & 0.738 & 0.710 & 0.681 \\
$a_{d}$ & 0.888 & 0.782 & 0.751 & 0.840 & 0.786 & 0.730 \\
$a_{x}$ & 0.491 & 0.476 & 0.552 & 0.644 & 0.637 & 0.629 \\
$a_{x}^{*}$ & 0.387 & 0.528 & 0.547 & 0.419 & 0.495 & 0.559 \\
\hline \hline \multirow{7}{*}{} & \multicolumn{7}{|c|}{ revenue requirement $\bar{R}=0.20$} \\
\hline & $\tau^{*}=0.5$ & \multicolumn{2}{|c|}{$\tau^{*}=0$} & \multicolumn{2}{c|}{$\tau=0$} & $\tau^{*}=0$ \\
\hline \multirow{2}{*}{$\tau=0.5$} & $\tau=0.5$ & $\tau=0.2$ & $\tau^{*}=0.5$ & $\tau^{*}=0.2$ & $\tau=0$ \\
\hline$\delta$ & 0.954 & 0.946 & 0.720 & 0.578 & 0.570 & 0.561 \\
$\Delta$ & 1.007 & 1.008 & 1.041 & 1.068 & 1.066 & 1.064 \\
& 0.849 & 0.862 & 0.895 & 0.907 & 0.912 & 0.918 \\
\hline
\end{tabular}

Note: Parameter values that are held constant in all simulations: $\varepsilon=2, a_{0}=1, \theta=2$, $\mu=\mu^{*}=0.8, P^{*}=0.7, K=2, N^{e *}=1, F_{d}=0.3 \mu, F_{x}=F_{x}^{*}=1.1 F_{d}$. 
The effects at the firm level illustrate the results of our analysis above. In particular, an isolated reduction in $\tau$ increases the number of domestic exporters (i.e. the direct effect in (35) dominates the indirect effect), whereas a reduction in $\tau^{*}$ reduces the number of domestic exporters from the indirect effect working through the induced policy change. Finally, comparing the first and the last column in Table 2 shows that a simultaneous and equal reduction in $\tau$ and $\tau^{*}$ reduces the number of domestic firms but increases the number of domestic exporters. This shift in production towards more productive firms unambiguously raises aggregate profits in the home country. The expansion of the domestic tax base and the reduced capital subsidies that are induced by economic integration thus allow a sharp drop in the statutory profit tax rate $t$ for any given level of tax revenue requirements.

\section{Conclusion}

Over the past thirty years, most countries have enacted corporate tax reforms that have combined significant reductions in corporate tax rates with some broadening of corporate tax bases. For debt-financed investments, which were heavily subsidized until the 1980s, these tax reforms have brought a significant reduction in the implicit subsidy rate, and a corresponding increase in the cost of capital. In the present paper we have linked this development to increasing economic integration using a model of imperfectly competitive, heterogenous firms.

We begin by showing that, as a result of imperfect competition, the government of a small country has an incentive to offer capital subsidies in order to increase output and, eventually, domestic consumption. When trade barriers fall, there are two reasons to reduce the optimal capital allowance. First, economic integration decouples production and consumption in the home country, reducing the effectiveness of capital subsidies as a means of increasing domestic consumption. This effect would also arise in a model of homogeneous firms. As a second effect, however, capital subsidies lead to additional inefficiencies in the presence of heterogeneous firms, as they support low-productivity domestic producers while barring more productive foreign firms from the home market. These inefficiencies are exacerbated by economic integration and thus give a further reason for the government to reduce the subsidies to domestic firms. 
At the same time, this optimal policy reinforces the selection effects that are caused by increasing trade openness in a heterogeneous firms framework. In our model trade integration leads low-productivity home firms to exit the domestic market both as a result of increased foreign competition and as a result of reduced capital subsidies. Similarly, a larger number of foreign exporters enters the home country's market due to the direct effect of reduced trade barriers, but also because they are less discriminated against after the induced policy change in the home country. These results imply that a decline in trade barriers results in greater improvements to average productivity when tax policy is endogenous than when it is not.

One feature that is an undeniable part of the current economic landscape, but not a feature of our model, is the presence of foreign direct investment (FDI). In particular, if governments are limited in their ability to restrict capital subsidies to domesticallyowned firms the use of capital allowances would likely increase inbound FDI as foreigners seek out subsidized capital. Since the profits of such firms do not accrue to domestic citizens, we would expect that the optimal tax policy would be one that subsidizes capital less than we find here. The implications of declining inbound trade barriers for changes in the tax structure, however, likely depend on the motive for FDI. When it occurs to exploit comparative advantage (e.g. Bergstrand and Egger, 2007), falling trade costs would increase FDI. We would expect that this strengthens the incentive for the small country to increase the cost of capital for domestic firms. Alternatively, if FDI is horizontal, as in Helpman et al. (2004), declining trade costs would lead some foreign multinationals to revert to exporting, reducing FDI. This reduction in FDI might then remove some of the downward pressure on capital allowances. Similarly, the impact of changes in outbound trade costs would likely depend on the motive for outbound home FDI. We leave a detailed analysis of such possibilities to future work and hope that our paper serves as a useful springboard for these discussions. 


\section{Appendix}

\section{Appendix A: Proof of Proposition 1}

We start from the first-order condition for $\Delta$, which is repeated here for convenience:

$$
\frac{\partial}{\partial \Delta} \int_{0}^{a_{d}} \pi^{g}(a) d G+\int_{0}^{a_{d}} k(a) d G+(\Delta-1) \frac{\partial}{\partial \Delta} \int_{0}^{a_{d}} k(a) d G-\frac{\mu}{P} \frac{\partial P}{\partial \Delta}=0 .
$$

Differentiating the maximized domestic profit function for a single firm with respect to $\Delta$ and collecting terms gives

$$
\frac{\partial \pi_{d}^{g}}{\partial \Delta}=\left(\frac{\partial q_{d}}{\partial \Delta}+\frac{\partial q_{d}}{\partial P} \frac{\partial P}{\partial \Delta}\right)\left[\frac{\partial p}{\partial q} q_{d}+p-\Delta \frac{\partial k_{d}}{\partial q_{d}}\right]+\frac{\partial p}{\partial P} \frac{\partial P}{\partial \Delta} q_{d}-k_{d}
$$

The first term in (A.2) is zero from the optimal output choice of firms. Differentiating the inverse demand function $p\left(q_{d}\right)$ and using $\alpha=(\varepsilon-1) / \varepsilon$ implies

$$
\frac{\partial p}{\partial P}=\alpha\left(\frac{\mu}{q_{d} P}\right)^{\frac{1}{\varepsilon}}
$$

Next, using the first-order condition for optimal quantities of exporters, the change in exporting profits is equal to

$$
\frac{\partial \pi_{x}^{g}}{\partial \Delta}=-k_{x}(a)
$$

Integrating over all firms in (A.2) and (A.4), using $\pi_{d}^{g}\left(a_{d}\right)=\pi_{x}^{g}\left(a_{x}\right)=0$ and combining with (A.1) gives eq. (22).

To show that the first term in (22) is negative, note first that $\partial P / \partial \Delta>0$ from (20). Moreover,

$$
\int_{0}^{a_{d}} \frac{\partial p}{\partial P} \frac{P q_{d}}{\mu} d G(a)=\alpha\left(\frac{P}{\mu}\right)^{\alpha} \int_{0}^{a_{d}} q_{d}^{\alpha} d G(a) \leq \alpha\left(\frac{P X}{\mu}\right)^{\alpha}=\alpha
$$

where the first equality follows from exchanging variables, the inequality is strict when imports are positive, and the last equality follows from $\mu=P X$. Since $\alpha<1$ the squared bracket in the first term of (22) must be negative.

It remains to show that

$$
\frac{\partial}{\partial \Delta} \int_{0}^{a_{i}} k_{i}(a) d G=\frac{\partial a_{i}}{\partial \Delta} k_{i}\left(a_{i}\right) g\left(a_{i}\right)+\int_{0}^{a_{i}} \frac{\partial k_{i}(q(\Delta))}{\partial \Delta} d G<0 \quad \forall i \in\{d, x\} .
$$


For $i=x$ this must always be fulfilled since $\partial a_{x} / \partial \Delta<0$ from (16) and $\partial k_{x} / \partial \Delta<0$ from (11) and (5). For $i=d$ the direct effects of $\Delta$ are analogous, but there is a counteracting effect from the increase in the price level $(\partial P / \partial \Delta>0)$ on $k_{d}$. To see that the net effect is negative, and thus $\Delta<1$, we verify $\frac{\partial}{\partial \Delta} \int_{0}^{a_{d}}\left(a q_{d}+F\right) d G<0$. The effect of $\Delta$ on $P$ is via the domestic producers (labeled $N$ ) and via the mass of foreign exporters (labeled $M^{*}$ ) which depends on the foreign export cutoff.

We define an auxiliary variable

$p_{M}(\Delta) \equiv \int_{0}^{M^{*}} p_{x}^{*}(j)^{-(\varepsilon-1)} d j=M^{*} \int_{0}^{a_{x}^{*}} p_{x}^{*}(a)^{-(\varepsilon-1)} \frac{g^{*}(a)}{G\left(a_{x}^{*}\right)} d a=\int_{0}^{a_{x}^{*}} p_{x}^{*}(a)^{-(\varepsilon-1)} d G^{*}(a)$,

which is increasing in $\Delta$ :

$$
\frac{\partial p_{M}}{\partial \Delta}=\underbrace{\frac{\partial a_{x}^{*}}{\partial P}}_{>0} \underbrace{\frac{\partial P}{\partial \Delta}}_{>0} p_{x}^{*}\left(a_{x}^{*}\right)^{-(\varepsilon-1)} g\left(a_{x}^{*}\right)>0 .
$$

With this notation,

$$
P^{-(\varepsilon-1)}=\int_{0}^{N} p_{d}(j)^{-(\varepsilon-1)} d j+\int_{0}^{M^{*}} p_{x}^{*}(j)^{-(\varepsilon-1)} d j=\int_{0}^{a_{d}}\left(\frac{\Delta a}{\alpha}\right)^{-(\varepsilon-1)} d G+p_{M}(\Delta) .
$$

Together with the optimal quantities this allows us to write

$$
\int_{0}^{a_{d}} a q_{d}(a) d G=P^{\varepsilon-1} \frac{\mu \alpha}{\Delta}\left[\int_{0}^{a_{d}}\left(\frac{\Delta a}{\alpha}\right)^{-(\varepsilon-1)} d G\right]=\frac{\mu \alpha}{\Delta}\left[1-P^{\varepsilon-1} p_{M}\right] .
$$

It follows that $\frac{\partial}{\partial \Delta} \int_{0}^{a_{d}} a q(\cdot) d G<0$ as $P^{\varepsilon-1} p_{M}$ is increasing in $\Delta$. To show that $\frac{\partial}{\partial \Delta} \int_{0}^{a_{d}} k_{d} d G<0$ we are thus left to prove that $\partial a_{d} / \partial \Delta<0$.

By continuity, this amounts to verifying that $\pi_{d}\left(a_{d}\right)$ is decreasing in $\Delta$, which from eq. (12) requires $\Delta / P$ to be increasing in $\Delta$ for given $a_{d}$. Using (A.7) and (A.8), this is immediate from

$$
\left(\frac{\Delta}{P}\right)^{\varepsilon-1}=\int_{0}^{a_{d}}\left(\frac{a}{\alpha}\right)^{-(\varepsilon-1)} d G+\Delta^{\varepsilon-1} p_{M}(\Delta) .
$$

This completes the proof.

\section{Appendix B: Derivation of equation (25)}

In a first step we derive the solution for the three cutoff variables $a_{d}, a_{x}$ and $a_{x}^{*}$ and the price index $P$ under the Pareto distribution. Noting that the derivative of the Pareto 
distribution function (23) (i.e., the density function) is

$$
G^{\prime}(a) \equiv g(a)=\frac{\theta a^{(\theta-1)}}{a_{0}^{\theta}},
$$

we obtain

$$
\begin{aligned}
& (\alpha P)^{\theta}=\frac{\left(1-\frac{\varepsilon-1}{\theta}\right) a_{0}^{\theta}\left(\frac{\varepsilon}{\mu}\right)^{\frac{\theta}{\varepsilon-1}-1}}{\left(\frac{1}{\Delta}\right)^{\varepsilon \frac{\theta}{\varepsilon-1}-1}\left(\frac{1}{F_{d}}\right)^{\frac{\theta}{\varepsilon-1}-1}+\left(\frac{1}{\Delta^{*}}\right)^{\frac{\theta}{\varepsilon-1}-1}\left(\frac{1}{1+\tau^{*}}\right)^{\theta}\left(\frac{1}{F_{x}^{*}}\right)^{\frac{\theta}{\varepsilon-1}-1}} \\
& \left(\frac{a_{d}}{a_{0}}\right)^{\theta}=\frac{\left(1-\frac{\varepsilon-1}{\theta}\right)\left(\frac{\mu}{\varepsilon}\right)}{\Delta F_{d}\left\{1+\left(\frac{\Delta}{\Delta^{*}}\right)^{\varepsilon \frac{\theta}{\varepsilon-1}-1}\left(\frac{1}{1+\tau^{*}}\right)^{\theta}\left(\frac{F_{d}}{F_{x}^{*}}\right)^{\frac{\theta}{\varepsilon-1}-1}\right\}} \\
& \left(\frac{a_{x}^{*}}{a_{0}}\right)^{\theta}=\frac{\left(1-\frac{\varepsilon-1}{\theta}\right)\left(\frac{\mu}{\varepsilon}\right)}{\Delta^{*} F_{x}^{*}\left[1+\left(1+\tau^{*}\right)^{\theta}\left(\frac{F_{x}^{*}}{F_{d}}\right)^{\frac{\theta}{\varepsilon-1}-1}\left(\frac{\Delta^{*}}{\Delta}\right)^{\varepsilon \frac{\theta}{\varepsilon-1}-1}\right]} \\
& \left(\frac{a_{x}}{a_{0}}\right)^{\theta}=\left(\frac{1}{1+\tau}\right)^{\theta}\left(\frac{F_{d}^{*}}{F_{x}}\right)^{\frac{\theta}{\varepsilon-1}}\left(\frac{\Delta^{*}}{\Delta}\right)^{\varepsilon \frac{\theta}{\varepsilon-1}} N^{*}
\end{aligned}
$$

with the comparative static properties with respect to $\Delta$ :

$$
\frac{\partial P}{\partial \Delta}>0, \quad \frac{\partial a_{d}}{\partial \Delta}<0, \quad \frac{\partial a_{x}^{*}}{\partial \Delta}>0, \quad \frac{\partial a_{x}}{\partial \Delta}<0,
$$

which follow from (B.2)-(B.5) and $\theta>\varepsilon-1, \varepsilon>1$.

Next we rewrite the indirect utility function (21) in a more compact form. From the definition of (8) the first and the second term in (21) can be combined, cancelling the $\Delta$ terms. This gives

$$
\tilde{V}=\int_{0}^{a_{d}}\left(\rho_{d}-k_{d}\right) d G+\int_{0}^{a_{x}}\left(\rho_{x}-k_{x}\right) d G-\mu \ln P,
$$

where $\tilde{V} \equiv V-C$. We define

$$
\bar{a}_{i} \equiv\left[\int_{0}^{a_{i}} a^{-(\varepsilon-1)} \frac{d G}{G\left(a_{i}\right)}\right]^{-\frac{1}{\varepsilon-1}}, \quad i=\{d, x\} .
$$

Under the Pareto distribution, $\bar{a}_{d}$ and $\bar{a}_{x}$ are linear in the respective cutoffs:

$$
\bar{a}_{d}=\left[\frac{\theta-(\varepsilon-1)}{\theta}\right]^{\frac{1}{\varepsilon-1}} \equiv \bar{\theta}^{\frac{1}{\varepsilon-1}} a_{d}, \quad \bar{a}_{x}=\bar{\theta}^{\frac{1}{\varepsilon-1}} a_{x} .
$$

Inserting firms' price and quantity choices under the Pareto distribution gives

$$
\int_{0}^{a_{d}}\left(\rho_{d}-k_{d}\right) d G=\left\{\left(1-\frac{\alpha}{\Delta}\right)\left[\frac{P}{p_{d}\left(\bar{a}_{d}\right)}\right]^{\varepsilon-1} \mu-F_{d}\right\} G\left(a_{d}\right),
$$




$$
\int_{0}^{a_{x}}\left(\rho_{x}-k_{x}\right) d G=\left\{\left(1-\frac{\alpha}{\Delta}\right)\left[\frac{P^{*}}{p_{x}\left(\bar{a}_{x}\right)}\right]^{\varepsilon-1} \mu-F_{x}\right\} G\left(a_{x}\right) .
$$

Using (B.2) and (B.3) together with (B.8) in (B.9) gives

$$
\int_{0}^{a_{i}}\left(\rho_{i}-k_{i}\right) d G=\left[(\Delta-\alpha) \frac{\varepsilon}{\bar{\theta}}-1\right] F_{i} G\left(a_{i}\right), \quad i=\{d, x\} .
$$

From (B.11) and (B.2) we obtain the indirect utility function

$$
\tilde{V}_{1}=\left[(\Delta-\alpha) \frac{\varepsilon}{\bar{\theta}}-1\right]\left[F_{d} G\left(a_{d}\right)+F_{x} G\left(a_{x}\right)\right]+\frac{\mu}{\theta} \ln \left[\left(\frac{1}{\Delta}\right)^{\frac{\varepsilon \theta}{\varepsilon-1}-1}+\left(\frac{1}{1+\tau^{*}}\right)^{\theta}\left(\frac{F_{d}}{F_{x}^{*}}\right)^{\frac{\theta}{\varepsilon-1}-1}\right]
$$

where $\tilde{V}_{1}$ is a monotonous transformation of $\tilde{V}$, with $\tilde{V}_{1} \equiv \tilde{V}+\ln \left[\frac{a_{0} \bar{\theta}^{\frac{1}{\theta}} \frac{\varepsilon F_{d}}{\mu}{ }^{\frac{1}{\varepsilon-1}-\frac{1}{\theta}}}{\alpha}\right]^{\mu}$.

The optimality condition derived from (B.12) is given by

$$
\begin{aligned}
& \frac{\varepsilon}{\bar{\theta}}\left[F_{d} G\left(a_{d}\right)+F_{x} G\left(a_{x}\right)\right]+\left[(\Delta-\alpha) \frac{\varepsilon}{\bar{\theta}}-1\right]\left[F_{d} g\left(a_{d}\right) \frac{\partial a_{d}}{\partial \Delta}+F_{x} g\left(a_{x}\right) \frac{\partial a_{d}}{\partial \Delta}\right] \\
= & \left(\varepsilon \frac{\theta}{\varepsilon-1}-1\right) \frac{\mu}{\theta} \frac{\Delta^{-\varepsilon \frac{\theta}{\varepsilon-1}}}{\left(\frac{1}{\Delta}\right)^{\varepsilon \frac{\theta}{\varepsilon-1}-1}+\left(\frac{1}{1+\tau^{*}}\right)^{\theta}\left(\frac{F_{d}}{F_{x}^{*}}\right)^{\frac{\theta}{\varepsilon-1}-1}} .
\end{aligned}
$$

The right-hand side of this expression can be simplified using

$$
\left(\frac{1}{\Delta}\right)^{\varepsilon \frac{\theta}{\varepsilon-1}-1}+\left(\frac{1}{1+\tau^{*}}\right)^{\theta}\left(\frac{F_{d}}{F_{x}^{*}}\right)^{\frac{\theta}{\varepsilon-1}-1}=\frac{\left(\bar{\theta} \mu / \varepsilon F_{d}\right)}{\Delta^{\varepsilon \frac{\theta}{\varepsilon-1}} G\left(a_{d}\right)}
$$

Further we use the properties of the Pareto distribution

$$
g\left(a_{d}\right)=\theta \frac{a_{d}^{\theta-1}}{a_{0}^{\theta}}=\frac{\theta}{a_{d}} G\left(a_{d}\right), \quad g\left(a_{x}\right)=\frac{\theta}{a_{x}} G\left(a_{x}\right) .
$$

Using (B.14) and (B.15) in (B.13), and substituting $\bar{\theta}=[\theta-(\varepsilon-1)] / \theta$, the first-order condition becomes

$$
\left[1+\frac{F_{x} G\left(a_{x}\right)}{F_{d} G\left(a_{d}\right)}\right]+\left[(\Delta-\alpha)-\frac{\bar{\theta}}{\varepsilon}\right]\left[\frac{\theta}{a_{d}} \frac{\partial a_{d}}{\partial \Delta}+\frac{F_{x} G\left(a_{x}\right)}{F_{d} G\left(a_{d}\right)} \frac{\theta}{a_{x}} \frac{\partial a_{x}}{\partial \Delta}\right]=\frac{\varepsilon}{\varepsilon-1}-\frac{1}{\theta}
$$

Next we calculate the derivatives $\partial a_{d} / \partial \Delta$ and $\partial a_{x} / \partial \Delta$ in (B.16). Defining

$$
a_{d}=\left[\frac{\frac{\bar{\theta} \mu}{\varepsilon \Delta F_{d}}}{1+\Delta^{\frac{\theta}{\varepsilon-1}-1}\left(\frac{1}{1+\tau^{*}}\right)^{\theta}\left(\frac{F_{d}}{F_{x}^{*}}\right)^{\frac{\theta}{\varepsilon-1}-1}}\right]^{\frac{1}{\theta}} a_{0} \equiv\left[\frac{\zeta}{\nu}\right]^{\frac{1}{\theta}} a_{0}
$$


the derivative of $a_{d}$ with respect to $\Delta$ is

$$
\frac{\partial a_{d}}{\partial \Delta}=\frac{a_{d}}{\theta}\left[\frac{\partial \zeta / \partial \Delta}{\zeta}-\frac{\partial \nu / \partial \Delta}{\nu}\right]
$$

where

$$
\frac{\partial \zeta / \partial \Delta}{\zeta}=-\frac{1}{\Delta}, \quad \frac{\partial \nu / \partial \Delta}{\nu}=\frac{\left(\varepsilon \frac{\theta}{\varepsilon-1}-1\right)}{\Delta} \frac{\Delta^{\varepsilon \frac{\theta}{\varepsilon-1}-1}\left(\frac{1}{1+\tau^{*}}\right)^{\theta}\left(\frac{F_{d}}{F_{x}^{*}}\right)^{\frac{\theta}{\varepsilon-1}-1}}{1+\Delta^{\varepsilon \frac{\theta}{\varepsilon-1}-1}\left(\frac{1}{1+\tau^{*}}\right)^{\theta}\left(\frac{F_{d}}{F_{x}^{*}}\right)^{\frac{\theta}{\varepsilon-1}-1}}
$$

This yields, using the definition of $\Gamma$ from (27) in the main text:

$$
\frac{1}{a_{d}} \frac{\partial a_{d}}{\partial \Delta}=-\frac{\Gamma(\Delta)}{\Delta \theta}
$$

Differentiating $\partial a_{x} / \partial \Delta$ is straightforward. Using (B.5) gives

$$
\frac{1}{a_{x}} \frac{\partial a_{x}}{\partial \Delta}=-\frac{\varepsilon}{\varepsilon-1} \frac{1}{\Delta} \text {. }
$$

Substituting (B.18)-(B.19) in (B.16) gives

$$
\left[1+\frac{F_{x} G\left(a_{x}\right)}{F_{d} G\left(a_{d}\right)}\right]-\frac{1}{\Delta}\left[(\Delta-\alpha)-\frac{\bar{\theta}}{\varepsilon}\right]\left[\Gamma(\Delta)+\varepsilon \frac{\theta}{\varepsilon-1} \frac{F_{x} G\left(a_{x}\right)}{F_{d} G\left(a_{d}\right)}\right]=\frac{\varepsilon}{\varepsilon-1}-\frac{1}{\theta} .
$$

The final step is to incorporate $G\left(a_{x}\right)$ and $G\left(a_{d}\right)$ under the Pareto distribution:

$$
\begin{gathered}
G\left(a_{x}\right)=\left(\frac{a_{x}}{a_{0}}\right)^{\theta}=\left(\frac{1}{1+\tau}\right)^{\theta} \Delta^{-\varepsilon \frac{\theta}{\varepsilon-1}}\left(\frac{F_{d}^{*}}{F_{x}}\right)^{\frac{\theta}{\varepsilon-1}} N^{*} \\
G\left(a_{d}\right)=\left(\frac{a_{d}}{\bar{a}}\right)^{\theta} \equiv \frac{(\bar{\theta} \mu / \varepsilon)}{\Delta F_{d}\left[1+\Delta^{\varepsilon \frac{\theta}{\varepsilon-1}-1}\left(\frac{1}{1+\tau^{*}}\right)^{\theta}\left(\frac{F_{d}}{F_{x}^{*}}\right)^{\frac{\theta}{\varepsilon-1}-1}\right]}
\end{gathered}
$$

Using this in (B.20) gives equation (25) in the main text. Moreover, using the definition of $\nu$ in (B.17) we can rewrite $G\left(a_{d}\right)$ as $G\left(a_{d}\right)=(\bar{\theta} \mu) /\left(\varepsilon \Delta F_{d} \nu\right)$. Using this and the definition of $\nu$ in (B.17) yields (26) in the main text.

\section{Appendix C: Proof of Proposition 2}

Consider first the opening up of imports. As long as the export channel remains closed $\left(F_{x} \rightarrow \infty\right), \chi=0$ holds from (28) and the optimality condition is:

$$
(1-\underbrace{\frac{1}{\varepsilon} \frac{\varepsilon-1}{\theta}}_{<1}) \frac{1}{\Delta}=1+\left(\frac{1}{\varepsilon-1}-\frac{1}{\theta}\right) \frac{1}{\Gamma(\Delta)} .
$$


In autarky, $\Gamma=1$. Opening up for imports, $\Gamma$ rises to a level $\Gamma>1$ when $F_{x}^{*}<\infty$. Hence the RHS of (C.1) is now smaller. For the LHS to also fall, $\Delta$ must increase. The fact that $\Delta=\alpha$ under autarky completes the proof for this case.

Consider next the case where the small country exports good $X$, but there are no imports. Hence $\Gamma=1$ from (28). The first-order condition (25) then simplifies to:

$$
\left\{1-\varepsilon \frac{\theta}{\varepsilon-1}\left[1-\frac{1}{\Delta}\left(1-\frac{1}{\varepsilon} \frac{\varepsilon-1}{\theta}\right)\right]\right\} \chi(\Delta)+\frac{1}{\Delta}\left(1-\frac{1}{\varepsilon} \frac{\varepsilon-1}{\theta}\right)=\frac{\varepsilon}{\varepsilon-1}-\frac{1}{\theta} .
$$

The LHS of (C.2) is strictly increasing in $\chi$, i.e. $1-\varepsilon \frac{\theta}{\varepsilon-1}\left[1-\frac{1}{\Delta}\left(1-\frac{1}{\varepsilon} \frac{\varepsilon-1}{\theta}\right)\right]>0$. To see this, suppose to the contrary that $\partial L H S / \partial \chi \leq 0$. This implies

$$
\begin{aligned}
1-\varepsilon \frac{\theta}{\varepsilon-1}\left[1-\frac{1}{\Delta}\left(1-\frac{1}{\varepsilon} \frac{\varepsilon-1}{\theta}\right)\right] & \leq 0 \\
(\varepsilon-1)-\varepsilon \theta & \geq[(\varepsilon-1)-\varepsilon \theta] \Delta .
\end{aligned}
$$

The term $(\varepsilon-1)-\varepsilon \theta$ must be negative since assuming to the contrary that $(\varepsilon-1)-$ $\varepsilon \theta \geq 0$ implies $\varepsilon-1>[(\varepsilon-1) / \varepsilon] \geq \theta$, a contradiction. Thus, supposing $\partial L H S / \partial \chi$ $\leq 0$ implies $1 \leq \Delta$, which is a contradiction to Proposition 1 . Thus, the LHS is strictly increasing in $\chi$. In autarky, $\chi=0$, and $\Delta=\alpha$. Allowing firms to export, $\chi$ jumps up to some $\chi>0$, so the LHS is now higher. Thus, as $\partial L H S / \partial \Delta<0, \Delta$ must increase to restore optimality.

The case where the economy simultaneously opens up for imports and exports combines the arguments made above. This completes the proof.

\section{Appendix D: Proof of Proposition 3}

As a preliminary step, we group the different measures of economic integration into two (non-exclusive) sets, $l=\left\{\tau, \tau^{*}, F_{x}, F_{x}^{*}\right\}$ and $j=\left\{\tau^{*}, F_{x}^{*}\right\}$. Differentiating $\chi$ in (26) and $\Gamma$ in $(27)$ with respect to these different measures of economic integration gives

$$
\frac{\partial \chi}{\partial l}<0, \quad \frac{\partial \Gamma}{\partial l}=0, \quad \frac{\partial \Gamma}{\partial j}<0
$$

Moreover, differentiating $\chi$ and $\Gamma$ with respect to $\Delta$ gives

$$
\frac{\partial \chi}{\partial \Delta}<0, \quad \frac{\partial \Gamma}{\partial \Delta}>0
$$


We start with part (a) of the Proposition, where there are no exports $(\chi=0)$, but there are imports $(\Gamma>1)$. The first-order-condition in this case is

$$
\frac{1}{\Delta} \underbrace{\left(1-\frac{\alpha}{\theta}\right)}_{>0}=1+\underbrace{\left[\frac{1}{\varepsilon-1}-\frac{1}{\theta}\right]}_{>0} \frac{1}{\Gamma(\Delta)} .
$$

Next, we define

$$
\bar{\Omega}=\frac{1}{\Delta} \underbrace{\left(1-\frac{\alpha}{\theta}\right)}_{>0}-1-\underbrace{\left[\frac{1}{\varepsilon-1}-\frac{1}{\theta}\right]}_{>0} \frac{1}{\Gamma(\Delta)}=0 .
$$

Starting from an interior optimum $\Delta^{*}$ in the initial equilibrium, it must be true that $\partial \bar{\Omega} / \partial \Delta<0$ for $\Delta>\Delta^{*}$. Moreover, for $j=\left\{\tau^{*}, F_{x}^{*}\right\}$

$$
\frac{\partial \bar{\Omega}}{\partial j}=\underbrace{\frac{\partial \bar{\Omega}}{\partial \Gamma}}_{>0} \underbrace{\frac{\partial \Gamma}{\partial j}}_{<0}<0 .
$$

Thus, by the implicit function theorem:

$$
\frac{\partial \Delta}{\partial j}=-\frac{\partial \bar{\Omega} / \partial j}{\partial \Omega / \partial \Delta}=-\frac{(<0)}{(<0)}<0
$$

which proves part (a) of Proposition 3.

Turning to part (b), the optimality condition without any restrictions on trade is:

$$
\Omega \equiv \underbrace{\left\{1-\varepsilon \frac{\theta}{\varepsilon-1} \tilde{\alpha}(\Delta)\right\}}_{>0} \chi(\Delta)-\tilde{\alpha}(\Delta) \Gamma(\Delta)-\left(\frac{1}{\varepsilon-1}-\frac{1}{\theta}\right)=0,
$$

where we define

$$
\tilde{\alpha}(\Delta) \equiv 1-\frac{1}{\Delta}\left(1-\frac{1}{\varepsilon} \frac{\varepsilon-1}{\theta}\right), \quad \tilde{\alpha}(\Delta)^{\prime}>0 .
$$

Since the initial equilibrium represents a maximum, it must be true that $\partial \Omega / \partial \Delta<0$ for $\Delta>\Delta^{*}$. Hence raising $\Delta$ is an optimal response to trade liberalization if and only if $\partial \Omega / \partial l<0$, where $l=\left\{\tau, \tau^{*}, F_{x}, F_{x}^{*}\right\}$. Differentiating $\Omega$ gives

$$
\frac{\partial \Omega}{\partial l}=\underbrace{\left\{1-\varepsilon \frac{\theta}{\varepsilon-1} \tilde{\alpha}(\Delta)\right\}}_{>0} \underbrace{\frac{\partial \chi}{\partial l}}_{<0}<0,
$$

proving part (b) of Proposition 3. 


\section{References}

Auerbach, A.J., Devereux, M.P., Simpson, H. (2010). Taxing corporate income. In: J. Mirrlees, S. Adam, T. Besley, R. Blundell, S. Bond, R. Chote, M. Gammie, P. Johnson, G. Myles and J. Poterba (eds), Dimensions of Tax Design: the Mirrlees Review, Oxford University Press, Chapter 9, 837-893.

Baldwin, R., Okubo, T. (2009). Tax reform, delocation and heterogeneous firms. Scandinavian Journal of Economics 111, 741-764.

Bergstrand, J.H., Egger, P. (2007). A knowledge-and-physical-capital model of international trade flows, foreign direct investment, and multinational enterprises. Journal of International Economics 73, 278-308.

Broda, C., Weinstein, D. (2006). Globalization and the gains from variety. Quarterly Journal of Economics 121, 541-585.

Chor, D., (2009). Subsidies for FDI. Implications from a model with heterogeneous firms. Journal of International Economics 78, 113-125.

Cole, M., (forthcoming). The choice of modeling firm heterogeneity and trade restrictions. Review of World Economics.

Cole, M. and R. Davies (2011). Optimal tariffs, tariff jumping, and heterogeneous firms. European Economic Review 55, 480-496.

Davies, R., Eckel, C. (2010). Tax competition for heterogeneous firms with endogenous entry. American Economic Journal: Economic Policy 2, 77-102.

Demidova, S., Rodriguez-Clare, A. (2009). Trade policy under firm-level heterogeneity in a small economy. Journal of International Economics 78, 100-112.

Devereux, M.P., Griffith, R., Klemm, A. (2002). Corporate income tax reforms and international tax competition. Economic Policy 35, 451-495.

Devereux, M.P., Lockwood, B., Redoano, M. (2008). Do countries compete over corporate tax rates? Journal of Public Economics 92, 1210-1235. 
Egger, P., Raff, H. (2007). Tax rate and tax base competition for foreign direct investment. Mimeo.

European Central Bank (2006). Financial stability review (December). Frankfurt.

Finke, K., Heckemeyer, J., Reister, T., Spengel, Ch. (2010). Impact of tax rate cut cum base broadening reforms on heterogeneous firms. ZEW Discussion Paper No. 10-036. Mannheim.

Flam, H., Helpman, E. (1987). Industrial policy under monopolistic competition. Journal of International Economics 22, 79-102.

Fuest, C., Hemmelgarn, T. (2005). Corporate tax policy, foreign firm ownership and thin capitalization. Regional Science and Urban Economics 35, 508-526.

Fuest, C., Huber, B., Mintz, J., 2005. Capital mobility and tax competition. Foundations and Trends in Microeconomics 1:1. Boston and Delft: Now Publishers.

Haufler, A., Schjelderup, G. (2000). Corporate tax systems and cross country profit shifting. Oxford Economic Papers 52, 306-325.

Helpman, E., Melitz, M., Yeaple, S. (2004). Export versus FDI with heterogeneous firms. American Economic Review 94, 300-316.

Jørgensen, J., and P. Schröder (2008). Fixed export cost heterogeneity, trade and welfare. European Economic Review 52, 1256-1274.

Keen, M., Klemm, A., Perry, V. (2010). Tax and the crisis. Fiscal Studies 31, 43-79.

Klemm, A., van Parys, S. (2009). Empirical evidence on the effects of tax incentives. IMF Working Paper No. 09/136. Washington, DC.

Krautheim, S., Schmidt-Eisenlohr, T. (2011). Heterogenous firms, 'profit shifting' FDI and international tax competition. Journal of Public Economics 95, 122-133.

Meade Committee (1978). The structure and reform of direct taxation. Allen and Unwin, London.

Melitz, M. (2003). The impact of trade on intra-industry reallocations and aggregate industry productivity. Econometrica 71, 1695-1725. 
OECD (2008). Revenue Statistics 1965-2007. Paris.

Pflüger, M., Südekum, J. (2009). Subsidizing firm entry in open economies. IZA Discussion Paper No. 4384. Bonn.

Sørensen, P.B. (1995). Changing views of the corporate income tax. National Tax Journal 48, 279-295. 